\title{
Application of coupled thermo-hydro-mechanical analysis to frost-heave behavior of earth structures
}

\author{
Tatsuya Ishikawa ${ }^{\text {i) }}$, Ippei Kijiya ${ }^{\text {ii) }}$, Tetsuya Tokoro ${ }^{\text {iii) }}$ and Masaru Sato ${ }^{\text {iv) }}$ \\ i) Professor, Faculty of Engineering, Hokkaido University, Kita 13 Nishi 8, Kita-ku, Sapporo 060-8628, Japan. \\ ii) Master Student, Graduate School of Engineering, Kita 13 Nishi 8, Kita-ku, Sapporo 060-8628, Japan. \\ iii) Assistant Professor, Tomakomai National College of Technology, 443 Nishikioka, Tomakomai 059-1275, Japan. \\ iv) Director, Geoscience Research Laboratory Co., Ltd., 3-1-6 Higashi, Yamato 242-0017, Japan.
}

\begin{abstract}
This paper presents numerical simulations on frost heave phenomenon observed at the earth structures and pavement structures using a coupled thermo-hydro-mechanical (THM) FE analysis, which can consider the change in deformation-strength characteristics and water retention-permeability characteristics due to freeze-thaw actions, and can reproduce frost-heave of soils under unsaturated conditions based on the results of frost heave tests. In order to evaluate the influences of freeze-thaw action on the interaction between frost-susceptible soil ground and structures quantitatively, a series of numerical simulations for cut slope and pavement structure subjected to freeze-thaw actions were performed. As the results, it was revealed that the coupled FE analysis employed in this study has a sufficient applicability to the precise prediction for the frost-heave behavior of soil ground, and that the frost-heave behavior has a considerable influence on the deformation and failure of earth structures in terms of the deformation and stress state of structures by examining the relation between frost heave and frost penetration depth.
\end{abstract}

Keywords: frost heave, geotechnical disaster, ground water level, unsaturated soils, cold regions

\section{INTRODUCTION}

In cold regions, the $0^{\circ} \mathrm{C}$ isotherm may penetrate deep into the soil ground, thereby causing the upheaval of slope surface or the cracking of the asphalt-mixture layer arising from the frost heave of frost-susceptible soil ground. Such phenomena specific to cold regions are thought to accelerate the deterioration of earth structures and pavement structures. However, little attention has been given to the frost-heave behavior of subsurface soils under unsaturated conditions. This paper presents numerical simulations on frost heave phenomenon observed at earth structures and pavement structures. First, a coupled thermo-hydro-mechanical (THM) FE analysis, which can consider the change in deformation-strength and water retention-permeability characteristics due to freeze-thaw actions, was newly developed. It also can reproduce frost-heave phenomenon of soils under saturated and unsaturated conditions based on the results of frost susceptibility tests. Subsequently, a series of numerical simulations on frost heave phenomenon observed at the cut slope around a drain ditch on berm and the pavement structure around a box culvert was conducted with the proposed FE analysis, and the validity of the numerical simulations was examined by comparing the results of numerical analyses with past results measured at the actual soil ground.

\section{NUMERICAL MODELING}

\subsection{Frost heave of unsaturated soils}

To examine the influence of the non-linear factors such as overburden pressure, freezing velocity, degree of saturation and water supply system on the frost heave behavior of soils, a series of frost heave tests of a frost-susceptible volcanic fine-grained soil, namely "Touryo soil" was carried out in conformance with the standard of the Japanese Geotechnical Society "Test method for frost heave prediction of soils (JGS 0171-2009)". The experimental conditions were changed in consideration of various factors which are thought to strongly influence the frost susceptibility of soils based on past researches (Michalowski 1993, Konrad and Nixon 1994, Hermansson and Guthrie 2005). Table 1 summarizes the experimental conditions of all tests and the results.

In Table 1, the frost heave behavior of Touryo soil strongly depends on experimental conditions. For examples, in case of frost heave tests with opened-system freezing, low overburden pressure, slow cooling rate and high degree of saturation tend to enhance the frost susceptibility. In addition, under slow cooling rate of $u=0.2{ }^{\circ} \mathrm{C} / \mathrm{h}$, the frost-susceptibility depends on overburden pressure, while under fast cooling rate of $u=0.4{ }^{\circ} \mathrm{C} / \mathrm{h}$ and $0.8{ }^{\circ} \mathrm{C} / \mathrm{h}$, the frost heave ratios are almost the same irrespective of 
Table 1. Test conditions of frost heave tests.

\begin{tabular}{lcccccc}
\hline Water supply & $\sigma_{a}(\mathrm{kPa})$ & $S_{r 0}(\%)$ & $\xi(\%)$ & $U(\mathrm{~mm} / \mathrm{h})$ & $U_{h}(\mathrm{~mm} / \mathrm{h})$ & $\Delta V_{w} / V_{0}$ \\
\hline Open system & 2.5 & 86.0 & 73.7 & 0.63 & 0.73 & 0.557 \\
\hline Open system & 5.0 & 81.7 & 55.8 & 0.77 & 0.69 & 0.423 \\
\hline Open system & 10.0 & 76.1 & 53.0 & 0.64 & 0.64 & 0.415 \\
\hline Open system & 50.0 & 81.0 & 25.9 & 0.98 & 0.34 & 0.229 \\
\hline Open system & 100.0 & 92.7 & 16.9 & 0.64 & 0.17 & 0.144 \\
\hline Open system & 200.0 & 82.7 & 3.3 & 1.07 & 0.03 & 0.034 \\
\hline Closed system & 2.5 & 82.5 & 15.1 & 2.28 & 0.64 & 0 \\
\hline Closed system & 5.0 & 78.9 & 15.7 & 2.44 & 0.56 & 0 \\
\hline Closed system & 10.0 & 76.6 & 14.4 & 2.73 & 0.53 & 0 \\
\hline
\end{tabular}

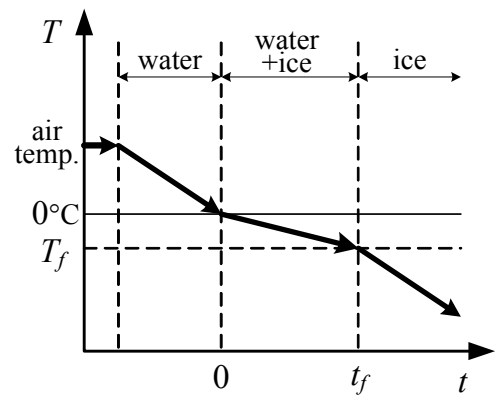

Fig. 1. Phase change from water to ice.

overburden pressure. These results are considered to be related to the growth of ice lens, which needs much water supply from unfrozen soil to frozen fringe (a transitional zone just behind a freezing front where soil is partially frozen). This is because insufficient water supply due to fast cooling rate results in the growth inhibition of ice lens. On the other hand, frost heave tests with closed-system freezing exhibit almost the same frost susceptibility, regardless of overburden pressure. The reason seems to be because the water content in a specimen for growth of ice lens is limited in frost heaving with closed-system freezing. These results indicate that the effects of freezing velocity and water supply system on the frost heave behavior are equivalent to that of water volume absorbed to geomaterials during freezing. Therefore, it seems reasonable to consider that three independent factors among all the experimental conditions, that is overburden pressure, degree of saturation and absorbed water volume, strongly affect the frost-susceptibility.

\subsection{Experimental equation for frost heave}

To reproduce frost heave phenomenon of soils under saturated and unsaturated conditions, this study introduced the frost expansion strain $\left(\varepsilon_{f}\right)$, which are generated by frost heave of soils over the temperature range of $0^{\circ} \mathrm{C}$ to the final freezing temperature of soil $\left(T_{f}\right)$ (Figure 1), into the constitutive model of the coupled THM FE analysis (Ishikawa et al. 2014). Based on the discussion in the preceding section, this study assumes that the frost expansion strain $\left(\varepsilon_{f}\right)$ can be expressed as:

$$
\varepsilon_{f}=\frac{\varepsilon_{f \max } S_{e 0}}{\zeta\left(\sigma_{a}^{\prime}+p_{s}\right)+1}+\zeta \frac{\Delta V_{w}}{V_{0}}
$$

$\varepsilon_{\text {fmax }}=$ maximum frost expansion strain of soil; $S_{e 0}=$ initial effective saturation; $\sigma^{\prime}{ }_{a}=$ effective overburden

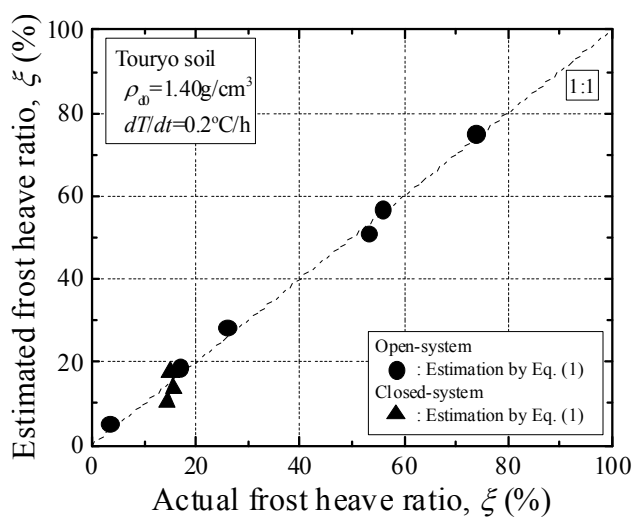

Fig. 2. Precision of estimated frost heave ratio.

pressure; $p_{s}=$ suction stress; $\Delta V_{w} / V_{0}=$ water volume absorbed to unit volume of soil from the surroundings per unit time; $\varsigma \& \zeta=$ constant parameter. The maximum frost expansion strain $\left(\varepsilon_{\text {fmax }}\right)$ is closely related to the frost heave ratio $(\xi)$ obtained from frost heave tests of soils.

Figure 2 compares actual frost heave ratio measured in frost heave tests under various experimental conditions with frost heave ratio calculated by Equation 1. The estimated values by Equation 1 agree well with the measured values, irrespective of experimental conditions such as overburden pressure, freezing velocity, degree of saturation and water supply system. Accordingly, it seems reasonable to conclude that Equation 1 proposed in this study has high applicability in the estimation of the frost heave behavior of geomaterials.

The main formulation of coupled THM FE analysis in this study, which considers the interaction among heat conduction through soils, water flow inside soils and deformation of soil skeleton, is as follows.

- Equilibrium equation:

$$
\frac{\partial \sigma_{i j}}{\partial t}=2 G \frac{\partial \varepsilon_{i j}}{\partial t}+\left(K-\frac{2 G}{3}\right) \frac{\partial \varepsilon_{k k}}{\partial t} \delta_{i j}+\frac{\partial \sigma_{0}}{\partial t} \delta_{i j}
$$

where $K=K_{d}+S_{e} K_{b}$

$$
\frac{\partial \sigma_{0}}{\partial t}=\frac{K_{b}}{\rho_{w}} \frac{\partial\left(\rho_{w} v_{i}\right)}{\partial x_{i}}-\left(n S_{e} \alpha_{w} K_{b}+\alpha K_{d}\right) \frac{\partial T}{\partial t}-K_{d} \frac{\partial \varepsilon_{f}}{\partial t}
$$

$\sigma_{i j}=$ stress; $\varepsilon_{i j}=$ deviator strain; $G=$ shear modulus of soil; $\delta_{i j}=$ Kronecker's delta; $\varepsilon_{k k}=$ normal strain; $K_{d}=$ bulk modulus of soil under drainage condition; $S_{e}=$ effective degree of saturation; $K_{b}=$ equivalent bulk modulus of pore water; $\rho_{w}=$ water density; $v_{i}$ $=$ average velocity of pore water in coordinate direction $x_{i} ; n=$ porosity; $\alpha, \alpha_{w}=$ thermal expansion coefficient of soil under drainage condition and pore water; $t=$ time; $T=$ temperature.

- Heat-conduction equation:

$$
C \rho \frac{\partial T}{\partial t}=-\frac{\partial}{\partial x_{i}}\left(k_{T} \frac{\partial T}{\partial x_{j}}\right)+C_{w} \rho_{w} \frac{\partial\left(v_{i} T\right)}{\partial x_{i}}
$$




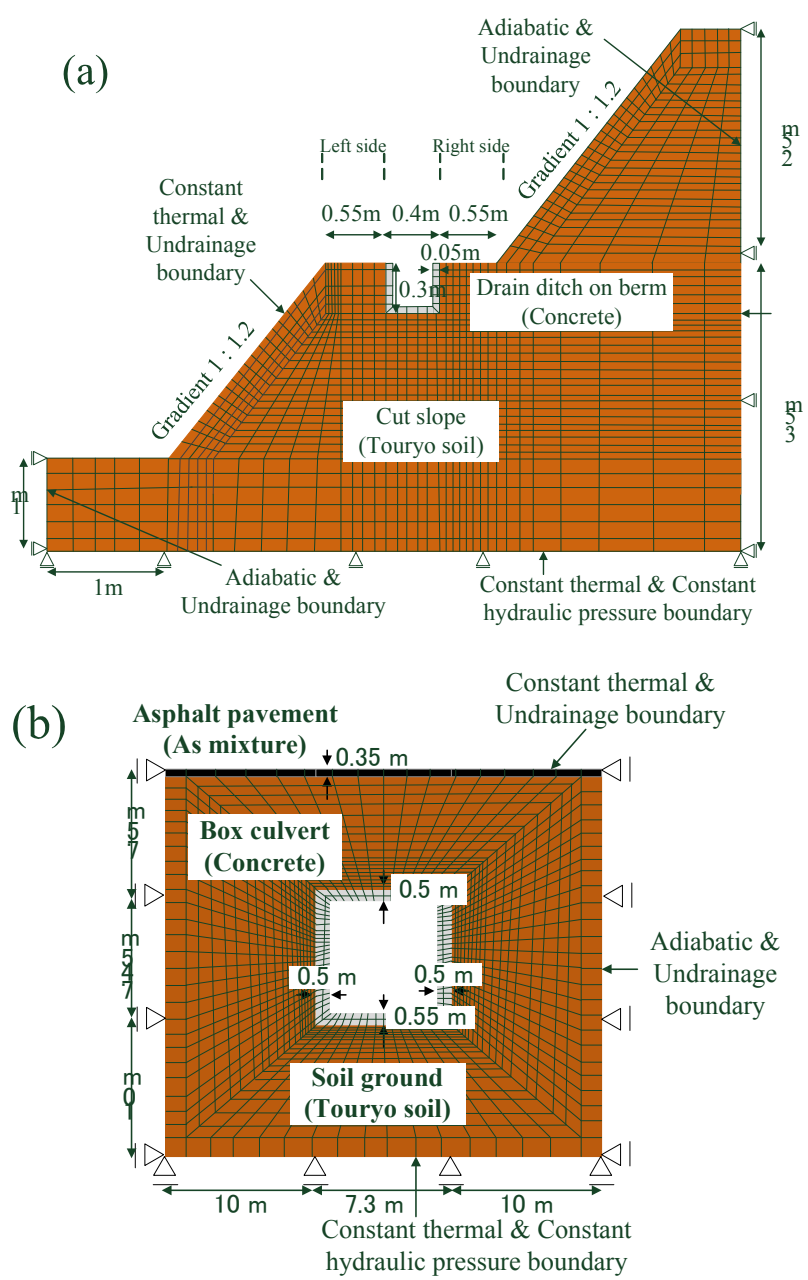

Fig. 3. Schematic diagrams of two-dimensional FE models (a: drain ditch model, b: box culvert model).

$C=$ specific heat at constant volume of wet soil; $\rho$ $=$ density of wet soil; $k_{T}=$ thermal conductivity of wet soil; $C_{w}=$ specific heat at constant volume of pore water.

- Seepage flow equation:

$$
\frac{1}{\rho_{w}} \frac{\partial\left(\rho_{w} v_{i}\right)}{\partial x_{i}}=\frac{1}{K_{b}} \frac{\partial u_{w}}{\partial t}+n S_{e} \alpha_{w} \frac{\partial T}{\partial t}-S_{e} \frac{\partial \varepsilon_{v}}{\partial t}
$$

$u_{w}=$ pore water pressure; $\varepsilon_{v}=$ volumetric strain .

\section{NUMERICAL SIMULATIONS}

\subsection{Finite element models}

In this study, a series of numerical simulations for frost heave phenomenon observed at the cut slope around a drain ditch on berm and the pavement structure around a box culvert under different analytical conditions was conducted with the above-mentioned coupled THM FE analysis. Figure 3 shows the size, dimension and boundary condition of two-dimensional FE models under plane-strain condition, together with the element mesh which consists of four-node quadrilateral elements. The cut slope and the pavement structure are the same size and shape as that of an in-situ model test in past research (Adachi et al. 2012, and Toyota et al. 2002). Note that soils which build up the cut slope and subgrade are assumed to be Touryo soil because the detail information about the soil properties were not reported in the past researches.

Boundary conditions of $\mathrm{FE}$ analysis were set as follows. As for the mechanical boundary condition, the base surface boundaries of both FE models were fixed in the vertical direction, and both lateral side boundaries were fixed in the horizontal direction. As for the hydraulic boundary condition, the undrainage boundary is imposed on both lateral sides, slope surface and top surface of FE models, while the constant hydraulic pressure boundary is set to the base surface. As for the thermal boundary condition, the adiabatic boundary is imposed on the both lateral sides, and the constant thermal boundary is imposed on the base surface, top surface and slope surface.

\subsection{Analytical conditions}

A FE simulation for frost heave phenomenon of the drain ditch model (Figure 3a) and the box culvert model (Figure 3b) were performed by dividing as follows. Note that the analytical conditions were determined with reference to the field measurements conducted by Adachi et al. 2012, and Toyota et al. 2002.

(1) Initial stability analysis: an initial distribution of moisture content and temperature inside FE model was calculated under a given ground water level and a prescribed thermal boundary condition so as to set the temperature of all elements at $8{ }^{\circ} \mathrm{C}$, and the gravity force of $9.80 \mathrm{~m} / \mathrm{s}^{2}$ was applied to estimate the stress state of all elements. Note that the constant hydraulic pressure boundary imposed on the base surface is altered depending on the ground water level of $0.0 \mathrm{~m}$ for the drain ditch model and $3.0 \mathrm{~m}$ for the box culvert model upward from base surface.

(2) Freeze process analysis: the FE model was frozen under a prescribed thermal boundary condition from the ground surface and the inner surface of the box culvert while keeping the temperature of base surface at $8{ }^{\circ} \mathrm{C}$. The temperature of ground surface in the drain ditch model was set at the in-situ air temperature during freezing period measured with the AMeDAS, while that of ground surface and culvert surface in the box culvert model was set at $-7.7{ }^{\circ} \mathrm{C}$ and the freeze process analysis was performed for 3055 hours by referring to mean air temperature during winter season and freezing index observed measured at the testing point.

(3) Thaw process analysis: the box culvert model was thawed under a prescribed thermal boundary condition from the ground surface and the inner surface of the box culvert. The temperature of ground surface and culvert surface was set at $8{ }^{\circ} \mathrm{C}$ 
Table 2. Input parameters of FE simulation.

\begin{tabular}{lc}
\hline Parameter name & Touryo soil \\
\hline Dry density of soil $\rho_{\mathrm{d}}$ & $1.40 \mathrm{~g} / \mathrm{cm}^{3}$ \\
\hline Porosity $n$ & 0.452 \\
\hline Deformation modulus before freeze-thawing $E_{0}$ & $6.0 \mathrm{MPa}$ \\
\hline Decreasing ratio of rigidity by freeze-thaw action $b$ & 0.0 \\
\hline Poisson's ratio of soil $v$ & 0.33 \\
\hline Hydraulic conductivity of saturated soil $k_{\mathrm{ws}}$ & $1.0 \times 10^{-8} \mathrm{~m} / \mathrm{s}$ \\
\hline Maximum degree of saturation $S_{\mathrm{rs}}$ & $96.7 \%$ \\
\hline Residual degree of saturation $S_{\mathrm{rr}}$ & $37.8 \%$ \\
\hline Thermal expansion coefficient of soil $\alpha$ & $1.20 \times 10^{-6} \mathrm{~K}-1$ \\
\hline Final freezing temperature of soil $T_{f}$ & $-0.2{ }^{\circ} \mathrm{C}$ \\
\hline Maximum frost expansion strain of soil $\varepsilon_{f \max }$ & $29.5 \%$ \\
\hline Thaw contraction strain of soil $\varepsilon_{f t}$ & $58.0 \%$ \\
\hline Specific heat at constant volume of dry soil $C_{\mathrm{d}}$ & $0.7 \mathrm{~kJ} / \mathrm{kgK}$ \\
\hline Thermal conductivity of soil $k_{\mathrm{T}}$ & $1.2 \mathrm{~W} / \mathrm{mK}$ \\
\hline Heat of solidification per unit volume of soil $Q_{l s}$ & $3.35 \times 10^{8} \mathrm{~J} / \mathrm{m}^{3}$ \\
\hline
\end{tabular}

and the thaw process analysis was performed for 1000 hours.

Table 2 summarizes the input parameters of FE simulation performed in this study. Note that the input parameters were set by referring to the results of various kinds of laboratory element tests for Touryo soil, and the common values employed in past researches and the like.

\section{RESULTS AND DISCUSSIONS}

\subsection{Frost heave behavior of drain ditch model}

Figure 4 shows the contour map of ground temperature inside the drain ditch model, the distribution of water-flow velocity vectors for all the finite elements, and the deformation behavior of the FE model at the end of freezing period (the elapsed time of 2236 hours), respectively. From Figure 4a, it can be recognized that a frozen soil layer parallel to the ground surface is formed at the subsurface layer of the model cut slope except for the immediate vicinities of the drain ditch on berm in freezing process, and that the $0{ }^{\circ} \mathrm{C}$ isotherm becomes deeper around the valley side (left side) of the drain ditch on berm as compared with the mountain side (right side). This is because the valley side of the drain ditch on berm was cooled off from two surfaces, that is berm surface and slope surface. These tendencies agree well with the past research (Adachi et al. 2012). In addition, from Figure $4 \mathrm{~b}$, it is observed that pore water flows into a frozen fringe (i.e. a transitional zone just behind a freezing front, where soil is partially frozen) from the surroundings with the passage of time during temperature drop. This result is considered to be related to the growth of ice lens, which needs much water supplied from unfrozen soil to frozen fringe. In this case, since a soil ground is frozen from the ground surface, ice lens begins to be produced from subsurface layer in case of slow cooling rate enough for the growth of ice lens. As the results, as shown in Figure 4c, the finite element located in the frozen area near the ground surface tend to expand in freezing process, though the slight differences in the direction of frost heave do exist
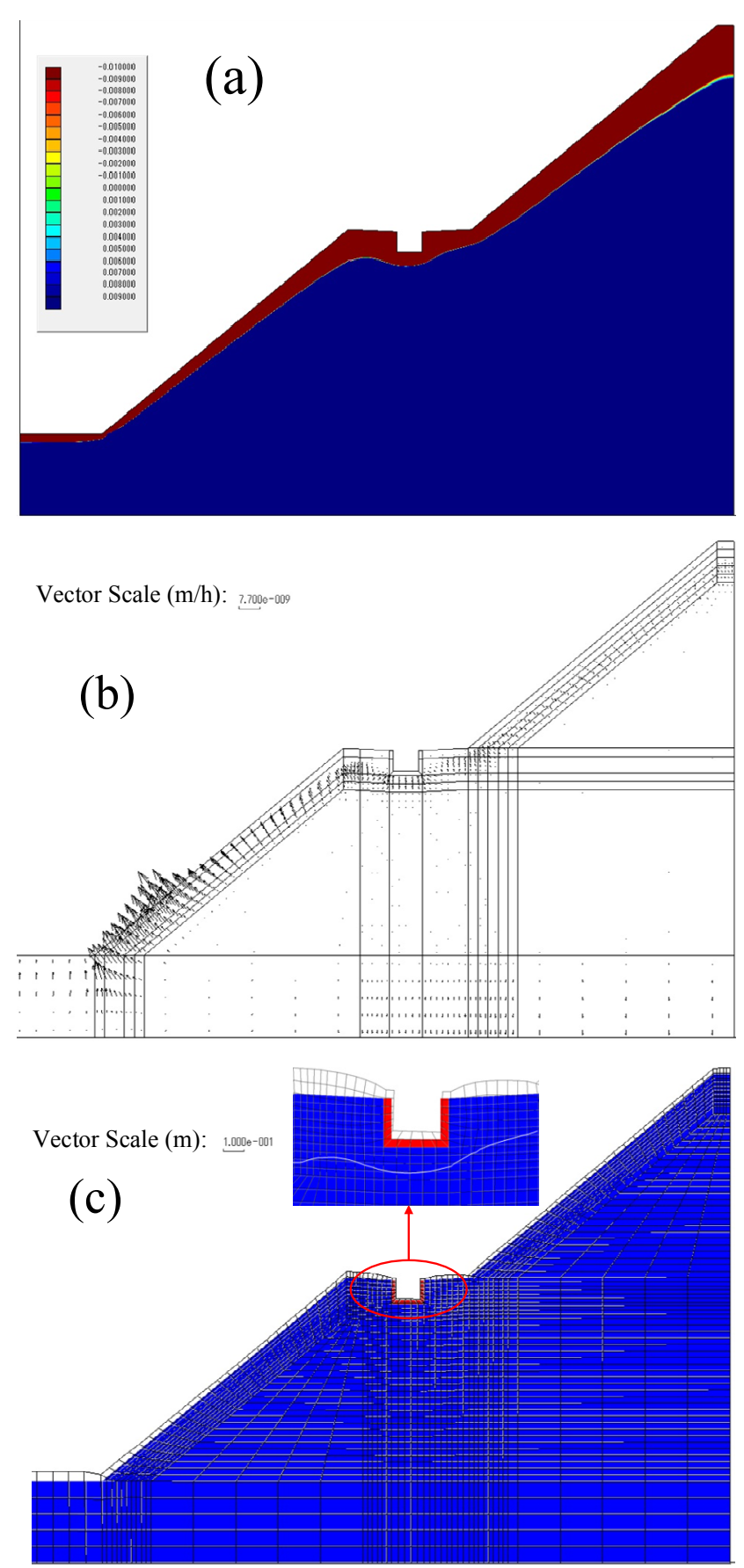

Fig. 4. Results of FE simulation for drain ditch model (a: contour map of ground temperature, $b$ : distribution of water-flow velocity vectors, c: deformation behavior).

owing to the effects of boundary conditions. For example, the surface layer at the valley side of the drain ditch on berm upheaves to the upper right during temperature drop, while the surface layer at the mountain side upheaves in a direction normal to the ground surface. This indicates that the differential frost heave of soil ground causes the drain ditch on berm to incline toward the mountain side.

In order to examine the validity of the coupled THM FE analysis, the deformation behavior of the drain ditch on berm obtained from the above-mentioned numerical 


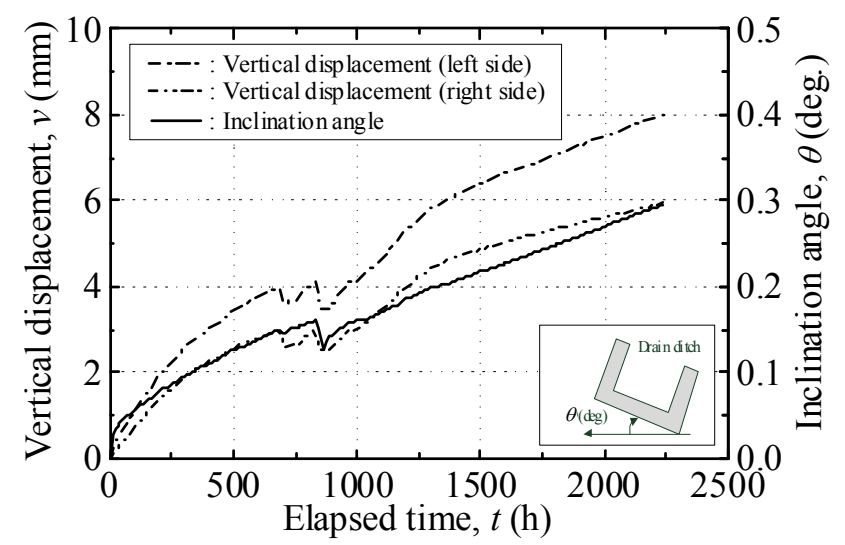

Fig. 5. Change in inclination of drain ditch with time.

simulation is compared to the measurement results at the in-situ cut slope from the viewpoint of the inclination of the drain ditch. Figure 5 shows time histories of the vertical displacement due to frost heave of soil ground at different locations around the drain ditch during the freeze process analysis. It also shows the change in the inclination angle of the drain ditch with time. Here, the inclination angle is calculated by dividing the difference in the upheaval between the right side wall and left side wall of the drain ditch with the width, and positive sign indicates clockwise rotation angle from the horizontal plane. According to Figure 5, it can be recognized that the FE simulation reproduces the change in differential upheaval of ground surface with the passage of time during temperature drop well, thereby increasing the inclination angle of drain ditch with time. The inclining tendency of drain ditch on berm caused by frost heave of soil ground in FE simulation is similar to that of field measurement. Therefore, it appears reasonable to conclude that the newly developed coupled THM FE analysis has a high applicability to the numerical simulation for frost heave behavior of drain ditch on berm.

\subsection{Freeze-thaw behavior of box culvert model}

Figure 6 shows the contour map of ground temperature inside the box culvert model, the distribution of principal stress vectors for all the finite elements, and the deformation behavior of the FE model at the end of freezing period (the elapsed time of 3055 hours), respectively. Note that in Figure 6b, compression stress is given a blue arrow, and tension stress is given a red arrow. In Figure 6a, it is seen that two kinds of frozen soil layers parallel to the ground surface and the culvert surface are individually formed during freezing process analysis, and that the $0{ }^{\circ} \mathrm{C}$ isotherm penetrates deeply into frost-susceptible soil ground through the culvert. In addition, the subsurface layer over the box culvert freezes by cooling from two boundary conditions, that is ground surface and culvert surface, which results in deeper frost penetration depth around the box culvert. As the results, it can be recognized that the ground surface over the box culvert
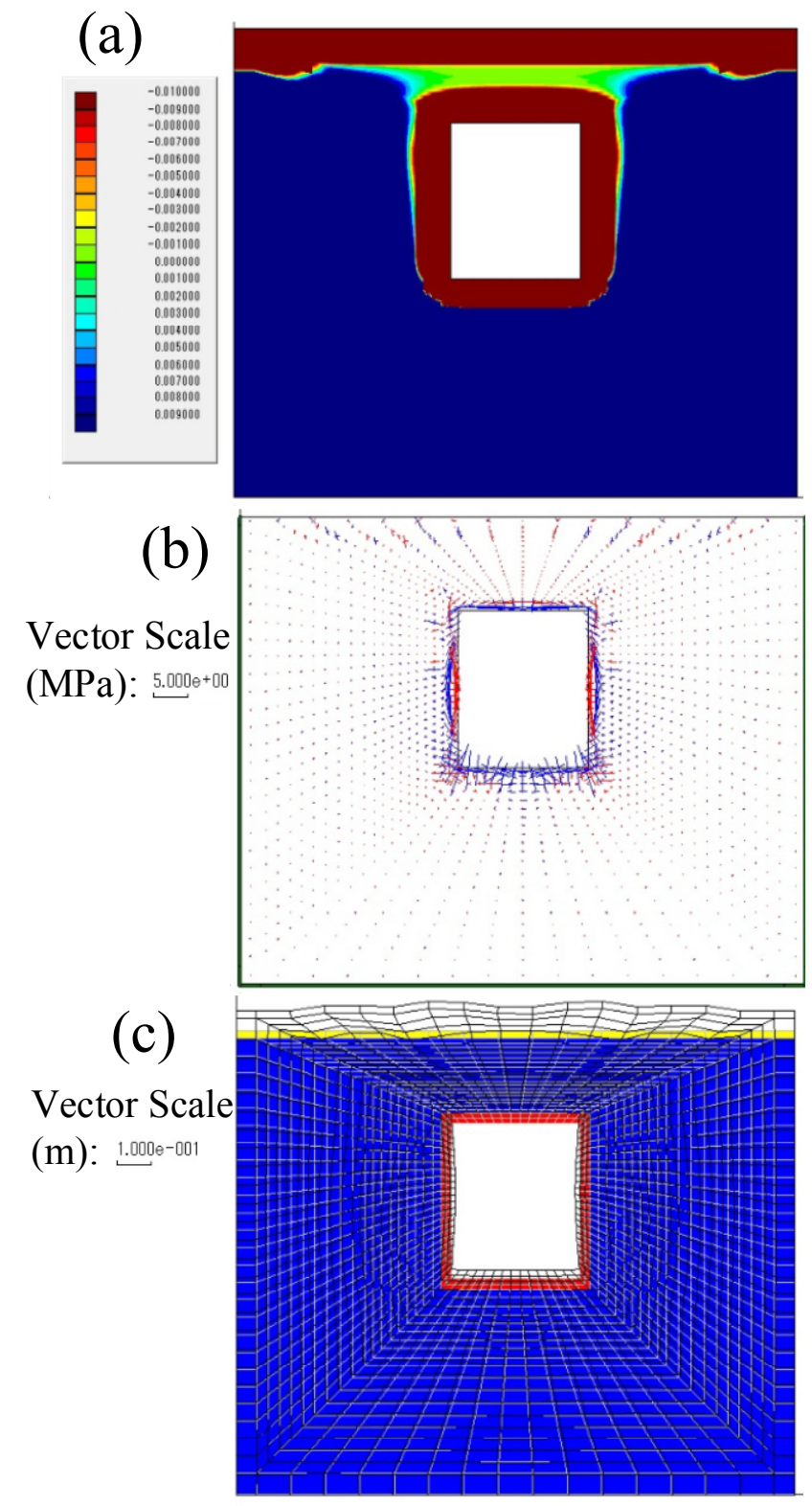

Fig. 6. Results of FE simulation for box culvert model (a: contour map of ground temperature, b: distribution of principal stress vectors, c: deformation behavior).

tends to upheave more in freeze process analysis as compared with the surrounding as shown in Figure 6c. Furthermore, the finite elements located in the frozen area near the ground surface tend to expand more in comparison with the frost heave inside the box culvert. This is because the frost heave behavior of the frozen area strongly depends on the stress state of finite elements as discussed in Chapter 2. For example, though low overburden pressure enhances the frost susceptibility of soils, as shown in Figure 6b, the principal stress near the ground surface is low, while the one near the box culvert is high. Accordingly, this difference in stress state is considered to be closely related to the frost heave behavior of soil ground. These results indicate that the formulation of coupled analysis in this study, which considers the interaction among 


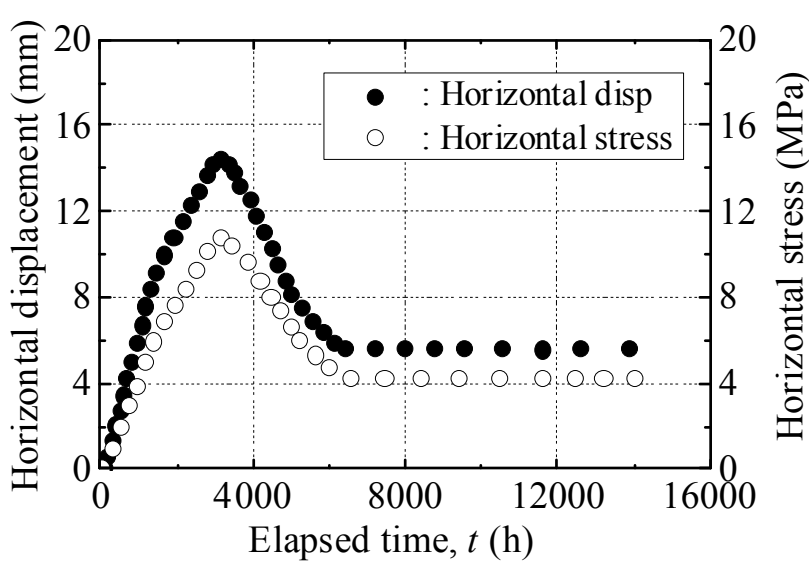

Fig. 7. Change in frost heave pressure of box culvert with time.

heat conduction through soils, water flow inside soils, and deformation of soil skeleton, functions properly.

Subsequently, the applicability of the coupled THM $\mathrm{FE}$ analysis is discussed by comparing the stress of box culvert measured at past field tests with the results of numerical simulation. Figure 7 shows time histories of the horizontal displacement and horizontal stress calculated at the center of inner side wall of box culvert due to frost heave of soil ground during freeze process analysis and thaw process analysis. As shown in Figure 6 , the finite element on the back of the box culvert expands toward the direction of heat flow in conformity with Equation 1 during temperature drop, and contracts during temperature rise, thus inducing the stress and strain exerted on the inner wall. In Figure 7, it is observed that the horizontal displacement caused by frost heave of soil ground gradually increases with time during temperature drop, and that in thaw process analysis after a lapse of about 3055 hours, the horizontal displacement starts to decrease due to thaw settlement. This trend of the horizontal displacement is closely related to the increase and decrease in horizontal stress. Furthermore, the horizontal stress obtained from this numerical simulation quantitatively agrees well with the past measured value of field tests (Toyota et al. 2002) when taking the difference in frost-susceptibility between soils used in this study and past research into account. Therefore, it seems reasonable to conclude that the coupled THM FE analysis proposed in this study is an effective method to estimate the fluctuations in the frost heave pressure exerted on the structures though there is room for further investigation on the precision improvement of the numerical simulation.

\section{CONCLUSIONS}

The main findings from this study are as follows:

- A proposed experimental equation of the frost expansion strain has high applicability in the estimation of the frost heave behavior of geomaterials.

- The inclining tendency of drain ditch on berm caused by frost heave of soil ground in FE simulation is similar to that of field measurement. Accordingly, the coupled FE analysis employed in this study has a sufficient applicability to the precise prediction for the frost-heave behavior of soil ground.

- FE simulation can capture the deformation behavior of box culvert caused by freeze-thaw action well. Therefore, the formulation of coupled FE analysis which considers the interaction among heat conduction through soils, water flow inside soils and deformation of soil skeleton, functions properly.

- The frost-heave behavior has a considerable influence on the deformation and failure of earth structures in terms of the deformation and stress state of structures.

\section{ACKNOWLEDGEMENTS}

This research was supported in part by Grant-in-Aid for Scientific Research (B) (23360201) from Japan Society for the Promotion of Science (JSPS) KAKENHI.

\section{REFERENCES}

1) Adachi, T., Nishimoto, S., and Sato, A. (2012): Evaluation of frost heave force affecting berm ditches with the progress of freezing, Proceedings of Technical Report of the Annual Meeting of the JGS Hokkaido branch, 52, 1-8 (in Japanese).

2) Hermansson, A. and Guthrie, W.S. (2005): Frost heave and water uptake rates in silty soil subject to variable water table height during freezing, Cold Regions Science and Technology, 43(3), 128-139.

3) Ishikawa, T., Kijiya, I., Tokoro, T., and Sato, M. (2014): Numerical experiments on freeze-thaw of soils with coupled thermo-hydro-mechanical FE analysis, Proceedings of the 14th International Conference of the International Association for Computer Methods and Advances in Geomechanics, Kyoto, Japan, 415-420.

4) Konrad, J.-M. and Nixon, J.F. (1994): Frost heave characteristics of a clayey silt subjected to small temperature gradients, Cold Regions Science and Technology, 22(3), 299-310.

5) Michalowski, R. L. (1993): A constitutive model of saturated soils for frost heave simulations, Cold Regions Science and Technology, 22, 47-63.

6) Toyota, K., Yamaguchi, K., Saito, K., and Furukawa, T. (2002): Frost heaving properties of backfill soil around box-culvert, Proceedings of Technical Report of the Annual Meeting of the JGS Hokkaido branch, 42, 293-298 (in Japanese). 